\title{
Una tipología de espectadores teatrales en función de la influencia de diversos prescriptores y el uso de canales de información ${ }^{1}$
}

\section{A typology of theatre audiences based on the impact of various sources of influence and the use of information channels}
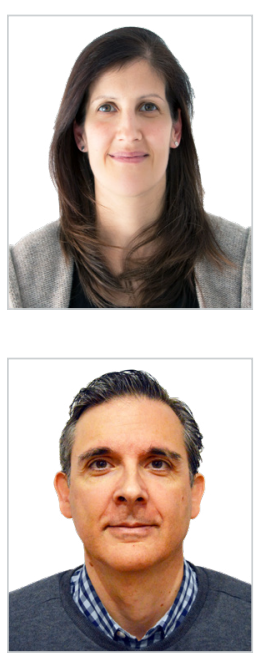

Recibido: 23/09/2019 - Aceptado: 25/01/2020

\section{Resumen:}

Este estudio presenta una tipología de espectadores teatrales que contempla la influencia de los medios de comunicación y otras instancias de prescripción en sus decisiones de asistencia al teatro, un aspecto no abordado por ninguna investigación previa. La in-

Universitat de València, España

malotor@alumni.uv.es

ORCID: 0000-0001-6654-130X

Universitat de València, España

ramon.llopis@uv.es

ORCID: 0000-0001-9336-2227
Ma Teresa Logroño Tormo. Licenciada en Comunicación Audiovisual y Doctora en Ciencias Sociales por la Universitat de València con la tesis "La contribución de las tecnologías digitales en el desarrollo del sector de las artes escénicas. Implicaciones en los procesos de creación, difusión y consumo y su influencia en los públicos de la ciudad de Valencia”. Completa su formación con el Máster en Gestión Cultural en la misma universidad. Ha trabajado como periodista en productoras audiovisuales y gabinetes de comunicación.

Ramón Llopis Goig. Doctor en Sociología. Catedrático y Vicedecano de Organización Académica de la Facultad de Ciencias Sociales de la Universidad de Valencia. Sus líneas de investigación se sitúan en el campo de la sociología del ocio, la cultura y el deporte. Entre sus publicaciones más recientes se encuentra Culturas en tránsito (Madrid, Fundación Autor, 2017) en coautoría con el profesor Antonio Ariño.

1 Este artículo se deriva de los resultados de una tesis doctoral defendida en la Universitat de València por la primera firmante y dirigida por el segundo (Logroño, 2018). Como en otras dos publicaciones previas (Logroño, 2016; Logroño y Llopis, 2017), este trabajo tiene su base empírica en la encuesta a espectadores teatrales a cuyo análisis se dedica uno de los capítulos de la mencionada tesis doctoral.

Cómo citar este artículo:

Logroño Tormo, M. T.; Llopis Goig, R. (2020). Una tipología de espectadores teatrales en función de la influencia de diversos prescriptores y el uso de canales de información. Doxa Comunicación, 30, pp. 127-143.

https://doi.org/10.31921/doxacom.n30a6 
vestigación se basa en una encuesta a 210 asistentes a representaciones teatrales de tres salas de la ciudad de Valencia. La aplicación de diversas técnicas estadísticas multivariables ha permitido identificar una tipología de cuatro perfiles de consumidores escénicos: los informados-alternativos, los documentados-receptivos, los distantes-independientes y los convencionales-comerciales. Esta tipología pone de manifiesto que los consumidores escénicos difieren en la influencia que sobre ellos tiene la presión mediática, el contenido temático de la representación o el prestigio y la notoriedad de la dirección y el reparto de la obra, así como en la intensidad con la que buscan información y consultan noticias y reseñas en los medios de comunicación.

Palabras clave:

Teatro; audiencias; comunicación cultural; medios de comunicación; sociología de la cultura.

\section{Introducción}

El conocimiento del comportamiento del consumidor de actividades culturales es de vital importancia para la gestión de las entidades que las ofertan. Facilita la planificación cultural, garantiza la viabilidad económica y permite desarrollar estrategias de estimulación de la audiencia (Colbert, 2007; Cuadrado, 1998; Ramón y Basso, 2010; Sellas y Colomer, 2009). El público está colocado en el centro del ciclo productivo (Jiménez, 2010) y constituye una fuente crucial para asegurar la sostenibilidad de las diferentes propuestas escénicas (Colombo, 2010; Fernández Torres, 2011). Este hecho es especialmente importante en el caso del teatro que, además, requiere la presencia física del público (Sánchez de Horcajo, 1999: 30). De ahí la importancia de disponer de un adecuado conocimiento de los públicos culturales -de sus comportamientos, características y perfiles tipológicos-, lo que permite una toma de decisiones fundamentada por parte de los responsables de la gestión de las entidades. La segmentación permite una identificación de los públicos a los que se dirige la oferta de actividades culturales, un mejor posicionamiento de la misma, una estructura de precios basada no solo en los costes sino también en las percepciones de los públicos y una estrategia de comunicación adecuada (Berenguer y Cuadrado, 2003).

Las investigaciones existentes han tenido en cuenta un amplio número de variables al estudiar el comportamiento de los públicos culturales. Sin embargo, el papel de la comunicación cultural ha sido escasamente analizado a este respecto, pese al aumento de canales informativos, la proliferación de publicaciones especializadas y la enorme cantidad de información que ofrece Internet, así como los cambios que se han producido en un ecosistema mediático en el que se ha alterado el flujo habitual entre emisor y receptor (Quintas y González, 2014). Todo ello ha hecho de la búsqueda de información cultural una variable imprescindible de cara a la construcción de nuevas tipologías de consumidores culturales.

Partiendo de las principales investigaciones y tipologías existentes sobre el consumidor de actividades escénicas, este trabajo ahonda en su heterogeneidad y propone una tipología basada en el uso que este tipo de consumidor hace de las noticias, reseñas y reportajes en la fase previa a la compra de una entrada, así como en la influencia que sobre el mismo 
tienen diversos medios de comunicación en tanto que transmisores de información y creadores de notoriedad de las obras teatrales. Entre las variables examinadas se encuentran factores como la presencia de información teatral en los medios de comunicación, la lectura de críticas y reseñas teatrales o la influencia de diversos prescriptores que refuerzan o inhiben la compra de una entrada.

Para llevar a cabo la investigación se elaboró un cuestionario ad hoc con el que se encuestó a 210 espectadores de tres salas teatrales ubicadas en la ciudad de Valencia. Este artículo se ha dividido en cuatro apartados que incluyen, en primer lugar, un planteamiento teórico en el que se da cuenta de las principales tipologías de espectadores teatrales propuestas en el ámbito de la comunicación y la gestión cultural. Posteriormente se incluye un apartado dedicado a las características técnicas y metodológicas de la investigación en el que se especifican los procedimientos de selección muestral y análisis estadístico. Por último, se exponen los resultados de la investigación y se presentan las conclusiones.

\section{Marco teórico}

En los últimos años, el sector cultural ha tomado conciencia de la importancia del público. En cierta medida, los espectadores han desplazado el protagonismo de la obra de arte y se han convertido en el centro de atención de los gestores culturales. La obra de arte o el producto cultural han pasado a ser comprendidos como un proceso social en el que la creación artística solo cobra tal dimensión a partir del reconocimiento del público (Jiménez, 2000; Ramón y Basso, 2010). Al mismo tiempo, las audiencias culturales se han hecho más heterogéneas y cada vez resulta más complicado descifrar sus hábitos y prácticas de consumo. Las nuevas tecnologías y formas de comunicación también están modificando los hábitos y las prácticas culturales. El nuevo paradigma digital está afectando a las formas de participación cultural dado que los cambios en los modos de comunicación de una sociedad -oral, letrada, audiovisual, digital- afectan de manera significativa el acceso a los bienes simbólicos, así como a la legitimidad de las formas culturales (Ariño, 2010: 11). En este contexto, es de gran importancia averiguar cómo y en qué medida los muy diversos procesos sociales, económicos y culturales que se desarrollan en la actualidad están dando lugar a una transformación del público teatral (Fernández Torres, 2012). Por ello, profundizar en el comportamiento, las motivaciones y las percepciones, así como en los factores que facilitan o dificultan la asistencia a un espectáculo teatral es esencial para diseñar acciones eficaces dirigidas a promover la asistencia de los espectadores, fidelizar los públicos y desarrollar nuevas demandas (Azpillaga, 2010; Nantel, 2007).

Los expertos y profesionales entrevistados por Sánchez de Horcajo (1999) ya apuntaban a la diversificación existente en los públicos del teatro. El crítico de teatro del diario ABC, Lorenzo López Sancho, señalaba que el teatro tiene numerosos y distintos públicos, algo que no sucedía en la década de 1950 cuando existían compañías de teatro estables y el público acudía a los teatros convencionales sabiendo a qué tipo de teatro asistía. Fernández Torres (1996) también señaló la inexistencia de un único público teatral en España. En su opinión, lo que realmente existe son públicos muy diferenciados derivados de la diversificación de la oferta.

Una primera diferenciación del público teatral -un tanto simplista- consistiría en clasificar el público en dos grandes categorías: el público aficionado que asiste al teatro buscando disfrute estético o formativo y el público ocasional que busca en el teatro un medio de esparcimiento. Urrutia (1991), reflexionando sobre la recepción teatral, afirmaba que "es 
preciso distinguir entre el espectador real, que acude cada tarde o cada noche a la sala de teatro, de ese otro espectador implícito (teórico) que el autor imagina en el momento de preparar su texto y tal vez nunca se haga real". El espectador implícito podría considerarse equivalente al espectador potencial. En este sentido, Berenguer y Cuadrado (2003) apuntan a la necesidad de considerar no solo a los consumidores presentes o asistentes a una actividad cultural sino también a los consumidores pasados y a los potenciales. De cualquier forma, resulta evidente que los públicos escénicos no son un conjunto homogéneo.

Los estudios de segmentación de los públicos escénicos se han basado principalmente en el estudio de los rasgos sociodemográficos, los estilos de vida, los valores culturales y los beneficios buscados, así como en los obstáculos que inhiben la asistencia al teatro. Por lo que se refiere a las variables sociodemográficas, Sellas y Colomer (2009) proponen clasificar a los espectadores según el nivel de estudios, el estilo de vida y la frecuencia con la que asisten a espectáculos teatrales.

La frecuencia de asistencia también ha sido el criterio de clasificación en numerosos estudios. Ateca-Amestoy (2008) distingue a los no asistentes y diferencia entre aquellos que no acuden nunca al teatro y aquellos que, a pesar de que no asisten, podrían estar interesados en asistir pero se encuentran con restricciones como el nivel de ingresos, el estado civil o el nivel educativo. Por su parte, López Sintas y García Álvarez (2002) segmentan a la audiencia en cuatro tipos diferenciados según el consumo y la frecuencia con la que asisten a representaciones de artes escénicas: los esporádicos, que muestran un patrón de bajo consumo ya que solo acuden de forma muy puntual, tanto si son productos más populares o más elitistas; los populares, que revelan una alta probabilidad de asistencia a espectáculos populares pero se mantienen ajenos a las artes escénicas y musicales cultas; los esnobs, que muestran una cierta probabilidad de asistencia, pero con pautas contrarias a los consumidores populares, ya que asisten únicamente a eventos de alta cultura como música clásica, ópera, zarzuela y danza; y los omnívoros, que como han propuesto algunos investigadores son aquellos que poseen un apetito insaciable por el consumo de diferentes géneros culturales (Ariño, 2010). Por su parte, Colomer (2013) clasifica los públicos de las artes escénicas según el estadio de consumo en que se encuentran y distingue entre públicos con demanda inexistente, públicos con demanda latente, públicos primerizos, públicos ocasionales, públicos regulares y amigos o socios.

Otras investigaciones ponen el foco en la parte intangible asociada a los productos culturales y proporcionan una relación de motivos de asistencia a las artes agrupándolos en función de las diferentes necesidades de los espectadores. Así, los consumidores pueden acudir por necesidades básicas -combatir el aburrimiento, búsqueda de nuevas experiencias-, necesidades sociales -entretenimiento, relación social-, necesidades personales -formación, enriquecimiento-, necesidades emocionales -relajación, escape- e ideales -estética, trascendencia-. En ese sentido, Wright (1962) dividió al público en tres grupos: los escapistas, que acuden al teatro para olvidar sus responsabilidades y problemas cotidianos; los moralistas, aquellos que exigen al teatro que enseñe una lección; y los partidarios del arte por el arte, grupo constituido por los aficionados que desprecian los éxitos de taquilla y desestiman el teatro popular. Por su parte, Bergadàa y Nyeck (1995) delimitaron cuatro grupos de espectadores partiendo de esta misma variable: los que buscan entretenimiento y encuentran en el teatro una forma de descanso, un olvido de lo cotidiano y un aporte de placer; los que buscan diferenciación social y consideran el teatro como una experiencia artística solamente accesible a una élite social con ciertos conocimientos; los que buscan desarrollo personal y pretenden que el teatro les aporte enriquecimiento y estimulación 
intelectual; y los que buscan hedonismo social, que ven en el teatro como un modo de expresión cultural que les permite comunicarse con creadores, autores y actores.

En otro orden, Watson (1971) construyó una tipología de espectadores a partir del nivel de su implicación y compromiso y definió seis perfiles de espectadores derivados de la intersección entre el valor y la actitud hacia las artes. En relación con la valoración de las artes, Mayaux (1987) segmentó los públicos en intelectuales -que comprenden la cultura como una realidad social, tienen un capital cultural elevado y un nivel económico medio-; los burgueses -que consideran la cultura como tradición y tienen un capital cultural y económico elevado-; y los aspirantes -que entienden la cultura como diferenciación de clase y tienen un capital cultural y económico medio-.

Diversos han sido también los estudios que han analizado el consumo cultural desde la perspectiva de los beneficios buscados. Haley (1968) y Colbert y Cuadrado (2003) coinciden en considerar esta variable como una de las más determinantes en el proceso de toma de decisiones. De esta manera, un consumidor puede perseguir beneficios como goce intelectual, entretenimiento, integración social o aprendizaje, entre otros. Kelly (1987) concretó dos grupos de consumidores en el sector de las artes a partir de esta variable: los asistentes tradicionales, que han adquirido un gusto culturalmente definido a través de la socialización y la educación recibida; y los tecnológicos, que han recibido menos educación orientada a disfrutar la alta cultura y se muestran interesados por el consumo cultural porque buscan obtener cierto estatus y diferenciación de clase. Con posterioridad, Cuadrado (1998) agrupaba los beneficios buscados por la audiencia de actividades culturales en tres grupos: formativos, sociales y de disfrute. Los primeros se refieren a la búsqueda de fines educativos y valores de enriquecimiento personal. Los segundos están relacionados con la obtención de prestigio y relación social y los terceros se corresponden con la consecución de entretenimiento, diversión, placer y relajación.

En estudios posteriores, este último autor ha desarrollado otra tipología basada también en los beneficios buscados (Cuadrado, 2000; Cuadrado y Berenguer, 2002) que le ha permitido clasificar a los espectadores en: aspirantes, aquellos que consideran las actividades de naturaleza escénica principalmente como un modo de entretenimiento personal y aprendizaje -no con fines de relación social-; aficionados, aquellos que muestran una práctica más consolidada con mayor asistencia a conciertos de música clásica, ópera y ballet; entusiastas, aquellos que le otorgan mayor valoración a los diferentes beneficios buscados como la búsqueda de entretenimiento, el desarrollo intelectual y la existencia de una cartelera conocida; e indiferentes, aquellos que muestran apatía respecto a las artes escénicas y buscan únicamente entretenimiento. Los aficionados se muestran interesados por espectáculos escénicos relacionados con sus obras y artistas preferidos por lo que frecuentan principalmente espacios musicales y teatrales de programación conocida, mientras que los entusiastas acuden en mayor medida a entidades musicales y los indiferentes suelen asistir a entidades con programación de renombre. Bourdieu (2010) ya apuntó que los diferentes tipos de teatro acogen a públicos muy diferentes y diferenció entre el teatro comercial -con presencia de un público perteneciente a la clase dominante-y el teatro no comercial -al que acuden los denominados por el autor como intelectuales-. Por su parte, Colbert (2007) mostró que el teatro clásico y la música clásica generan un sentimiento de relajación; las comedias musicales y la música popular producen entretenimiento; la danza clásica y folclórica resultan estimulantes; y la ópera, el teatro experimental y la danza moderna contribuyen a aumentar el nivel cultural de los espectadores. 
La creciente importancia de las nuevas tecnologías en el consumo cultural está motivando una redefinición de los públicos de las artes escénicas y un mayor interés por las propuestas innovadoras. Por ello, la tendencia a la innovación se ha convertido, en los últimos años, en otra de las variables que más en cuenta se ha tenido. A este respecto, Sellas y Colomer (2009) han distinguido entre públicos de tendencia clásica -aficionados a lenguajes y formatos escénicos consolidados porque les proporcionan la seguridad de poderlos descodificar y disfrutar-; públicos de nuevas tendencias -aficionados a propuestas que parten de lenguajes y formatos consolidados aunque buscan cierto grado de innovación en incremento sin cambiar de código interpretativo-; y públicos con tendencia experimental -públicos que buscan propuestas que contengan estéticas y formatos emergentes y signifiquen una ruptura con los patrones dominantes-. Kotler y Scheff (1997), por otro lado, han distinguido cinco categorías en función del tiempo que precisan las personas para adoptar las innovaciones. Esto les lleva a plantear los siguientes perfiles: los innovadores, dispuestos a probar nuevas ideas y a asumir riesgos; los seguidores primerizos, líderes de opinión en sus comunidades ya que adoptan nuevas ideas de forma rápida; las personas prudentes, que adoptan las nuevas ideas antes que la mayoría pero sin ser líderes de opinión; los escépticos, que adoptan una innovación solamente después de que una mayoría la haya probado; y, finalmente, aquella parte de la población que vive sujeta a lo tradicional y que solamente adoptan una innovación cuando esta se convierte en tradición.

Pero más allá de los aspectos en que se basan los estudios mencionados, la presente investigación ha puesto su atención en la influencia de la comunicación cultural en la asistencia al teatro, ya que, como afirma Cantón, la capacidad de los medios de comunicación para promover o frenar el consumo cultural a través de prescriptores como las críticas, pone de manifiesto que la comunicación y la información cultural son "uno de los más influyentes cauces de conexión entre el arte y la sociedad” (Cantón, 2004). Más concretamente, en aspectos como la imagen y notoriedad adquirida por una obra de teatro en los medios de comunicación, el conocimiento de los actores y el director de la obra, la información que se proporciona de la misma a través de reportajes y comentarios, y el impacto de las críticas y reseñas de representaciones teatrales que se publican en los medios de comunicación.

Un trabajo que ha abordado -aunque muy tangencialmente- estos aspectos es el de Sellas y Colomer (2009), quienes distinguen tres tipos de públicos. En primer lugar, se refieren a un público con actitud proactiva, esto es, que participa en el hecho escénico a partir de un impulso que se origina en su sistema personal de valores. En segundo lugar, se refieren a un público con actitud reactiva. En este caso se trata de personas que asisten al teatro como respuesta a un estímulo exterior, a la recomendación de un amigo o a la influencia de los medios de comunicación. En tercer lugar, mencionan un público con actitud inactiva, es decir, que tiene interés pero que nunca ha asistido al teatro a causa de factores que bloquean la asistencia. En el primer caso se trataría de un consumo motivado por las preferencias personales de los espectadores (Colomer, 2013: 64; Sellas y Colomer, 2009), mientras que el segundo estaría condicionado por los valores de los grupos dominantes que ejercen el poder formal y económico a través de la publicidad, los estereotipos y la presión social (Colomer, 2013: 64). De hecho y en relación a este último aspecto, Colbert y d'Astous (2003) han construido una tipología para el ámbito cinematográfico en la que sostienen que el grado de consulta de las críticas depende de cuatro variables: el conocimiento cinematográfico, la autoestima del espectador, la sensibilidad a la presión social y el grado de implicación cultural. Su estudio concluía que las personas que más acuden al cine muestran menor influencia a las críticas, mientras que los que acuden menos son más propensos a reforzar sus decisiones con la búsqueda de información y la consulta de 
críticas. En el sector de las artes escénicas, sin embargo, no se ha construido ninguna tipología que contemple la influencia de los medios de comunicación en la facilitación de la asistencia al teatro así como el papel de los mismos transmitiendo información, reseñas y críticas teatrales, lo que precisamente constituye la principal aportación de este trabajo.

\section{Metodología}

\subsection{Muestra}

Para llevar a cabo la investigación se realizó una encuesta a espectadores de tres salas teatrales cuya programación está especializada en distintos géneros teatrales, lo que permite cubrir una amplia variedad de gustos teatrales y, por tanto, contar con diferentes perfiles de espectadores. La primera de ellas acoge a un público de teatro clásico y actual (Teatro Rialto), la segunda a un público de teatro comercial (Teatro Olympia) y la tercera a un público de teatro alternativo (Espacio Inestable). Se alcanzó una muestra de 210 entrevistas, que se distribuyeron a partes iguales entre las tres salas (70 entrevistas en cada sala) con la finalidad de obtener una muestra mínima para cada uno de los tipos de programación teatral. El trabajo de campo se realizó en la antesala de cada uno de los tres centros teatrales entre los meses de febrero y mayo del año 2012. La prolongación del trabajo de campo durante un periodo de tres meses tenía el propósito de asegurar la renovación del público y garantizar la mayor variedad en el conjunto muestral.

\subsection{Cuestionario}

La mayoría de las preguntas y opciones de respuesta con las que se diseñó el cuestionario aplicado en esta investigación se inspiraron en las que habitualmente se incluyen en las encuestas de prácticas culturales del Ministerio de Cultura o en los barómetros que el Centro de Investigaciones Sociológicas ha dedicado a estos temas. Sin embargo, dada la escasez de estudios de las características del que se pretendía llevar a cabo -es decir, centrados en la influencia de la información cultural y en el impacto de los medios de comunicación en la asistencia al teatro- las preguntas más específicas de esta investigación se diseñaron de manera expresa si bien se tuvieron en cuenta algunos trabajos -que han sido mencionados en el apartado dedicado al marco teórico- sobre la influencia de los medios de comunicación en el consumo y asistencia a espectáculos culturales en sectores como el cine o la música.

El cuestionario constaba de cuatro bloques de preguntas. Las del primer bloque tenían por objeto aportar información sobre los hábitos de consumo cultural y teatral de la persona entrevistada. El segundo bloque incluía un conjunto de preguntas destinadas a la obtención de información sobre los aspectos que facilitan la asistencia al teatro, así también como sobre la búsqueda de información sobre la programación cultural y el uso de Internet. El tercer bloque de preguntas se centró en la existencia de recomendaciones y en el grado de influencia que estas pueden llegar a ejercer en la persona entrevistada. El último bloque incluía las habituales preguntas de clasificación sociodemográfica. 


\subsection{Análisis de datos}

Para la obtención de una tipología de espectadores teatrales se ha seguido una secuencia de análisis que supone la concatenación de diversas técnicas estadísticas multivariables. En primer lugar, se seleccionaron 18 ítems del cuestionario cuyo contenido tenía que ver con los objetivos de esta investigación, es decir, con el consumo de artes escénicas, con la influencia de los medios de comunicación en el consumo teatral y con los comportamientos de búsqueda de información y lectura de reseñas y críticas teatrales. A continuación, se aplicó la técnica del análisis de componentes principales a los 18 ítems de partida con la intención de obtener su estructura latente. La aplicación de esta técnica mediante un procedimiento de rotación ortogonal (varimax) garantiza la independencia de los componentes y, por tanto, elimina la posibilidad de que esas dimensiones estén relacionadas entre sí, lo que dificultaría la ulterior aplicación de otras técnicas estadísticas sobre las dimensiones obtenidas. En tercer lugar, se ha obtenido una tipología de espectadores teatrales aplicando la técnica del análisis de conglomerados (cluster analysis) a las cinco dimensiones o componentes principales resultantes del análisis anterior. Finalmente se han realizado diversos análisis bivariables con el objeto de identificar las principales características sociodemográficas de cada conglomerado mediante la aplicación de la prueba estadística de Chi cuadrado.

\section{Resultados}

Con la finalidad de simplificar la información recogida en las dieciocho variables anteriores y prepararla para la elaboración de una tipología mediante el análisis de conglomerados, se procedió a la aplicación de la técnica del análisis factorial de componentes principales.

El primer análisis de componentes principales se aplicó a las variables del cuestionario relacionadas con la asistencia a seis tipos diferentes de actividades, espectáculos y centros culturales entre los que se encontraba el teatro. Se perseguía de ese modo identificar la posibilidad de que existiera un componente específico referido al consumo escénico. El modelo obtenido (tabla 1) arrojó la existencia de tres componentes que de manera conjunta explicaban un $64 \%$ de la varianza. Para llevar a cabo el análisis se prescindió de los componentes con valores propios o eigenvalues inferiores a la unidad y la rotación fue de tipo Varimax con Kaiser. La composición de cada uno de los tres componentes se realizó a partir de las saturaciones factoriales obtenidas en la matriz rotada. Se adoptó como criterio de saturación factorial las puntuaciones superiores a 0,45. El análisis, con un ajuste muestral de Káiser-Meyer-Olkin (KMO) de 0,601, fue significativo según el test de Bartlett. El primer componente surgido de este análisis está compuesto por las variables relativas a la asistencia e interés por el teatro, así como a la asistencia a espectáculos de danza. La configuración de este primer componente y el hecho de que sea el que obtiene la varianza más alta del primer modelo $(27,1 \%)$ es una prueba clara de la existencia de una dimensión independiente relativa a las artes escénicas. Ha sido etiquetado con la denominación de prácticas culturales escénicas. El segundo componente se compone de dos variables que incluyen la asistencia al cine y a conciertos musicales y ha sido denominado prácticas culturales modernas. Este componente explica un $19 \%$ de la varianza, una unidad porcentual más que el tercero, que recoge la covariación de la asistencia a bibliotecas, a museos y a exposiciones, por lo que ha sido denominado prácticas culturales ilustradas (véase tabla 1). 
El segundo análisis de componentes principales se aplicó a las variables que contenían información relativa a los diversos aspectos que influyen en la asistencia al teatro. Se logró un modelo de dos componentes principales que explican un $56,2 \%$ de la varianza ${ }^{2}$. El análisis obtuvo un ajuste muestral de 0,691 (KMO) y un contraste significativo en el test de Bartlett. El primero de los dos componentes obtenidos está integrado por cinco variables entre las cuales se encuentra la importancia de que se trate de una obra que tenga buenas críticas en prensa o televisión; que haya sido vista o anunciada en prensa y televisión; que sea famosa y se hable mucho de ella; que se la hayan recomendado o hablado bien; y que tenga un buen argumento. De acuerdo con el contenido de los mencionados ítems se decidió denominar a este componente presencia mediática y temática de la obra. El segundo componente de este segundo análisis estaba formado por dos variables referidas al conocimiento y reconocimiento de los actores y el director, por lo que se optó por denominarlo notoriedad y prestigio de los actores y el director.

Por último, el tercer análisis se aplicó a la información relacionada con la búsqueda de información y lectura de reseñas, críticas o reportajes teatrales con carácter previo a la asistencia al teatro. El análisis mostró la existencia de dos componentes que conjuntamente explicaban un $85,8 \%$ de la varianza. El análisis resultó significativo a nivel estadístico según el Test de Bartletty obtuvo un ajuste muestral de 0,525 (KMO). En el primero de los dos componentes que arrojó este modelo aparecían las variables relacionadas con la influencia de las reseñas, las críticas y los reportajes teatrales en la decisión de asistir al teatro, por lo que ha sido denominado influencia de las reseñas, las críticas y los reportajes en la asistencia al teatro. El otro componente ha sido denominado búsqueda de información y lecturas previas a la asistencia al teatro pues aglutina a las variables relacionadas con tales comportamientos.

Tabla 1: Análisis de componentes principales

\begin{tabular}{|l|c|c|c|}
\hline $\begin{array}{l}\text { Primer análisis de componentes principales (interés y asistencia a } \\
\text { espectáculos culturales) }\end{array}$ & $\begin{array}{c}\text { Saturaciones } \\
\text { factoriales }\end{array}$ & $\begin{array}{c}\text { Varianza } \\
\text { explicada }\end{array}$ & Denominación \\
\cline { 1 - 2 } En el último año, ¿̇cuántas veces ha acudido al teatro? & 0,808 & \multirow{2}{*}{$27,1 \%$} & Consumo e interés por el teatro \\
\cline { 1 - 2 } En el último año, ¿̇cuántas veces ha acudido a espectáculos de \\
danza?
\end{tabular}

2 El segundo y tercer análisis de componentes principales que aparecen en la tabla 1 ya han sido recogidos en un trabajo previo (Logroño y Llopis, 2017). No es ese el caso del primer análisis de componentes principales de la tabla 1 , ni de los análisis que aparecen en las tablas 2 , 3 y 4 , que son los que permiten abordar los objetivos de la presente investigación y constituyen la aportación específica de este trabajo. 
Una tipología de espectadores teatrales en función de la influencia de diversos prescriptores y el uso...

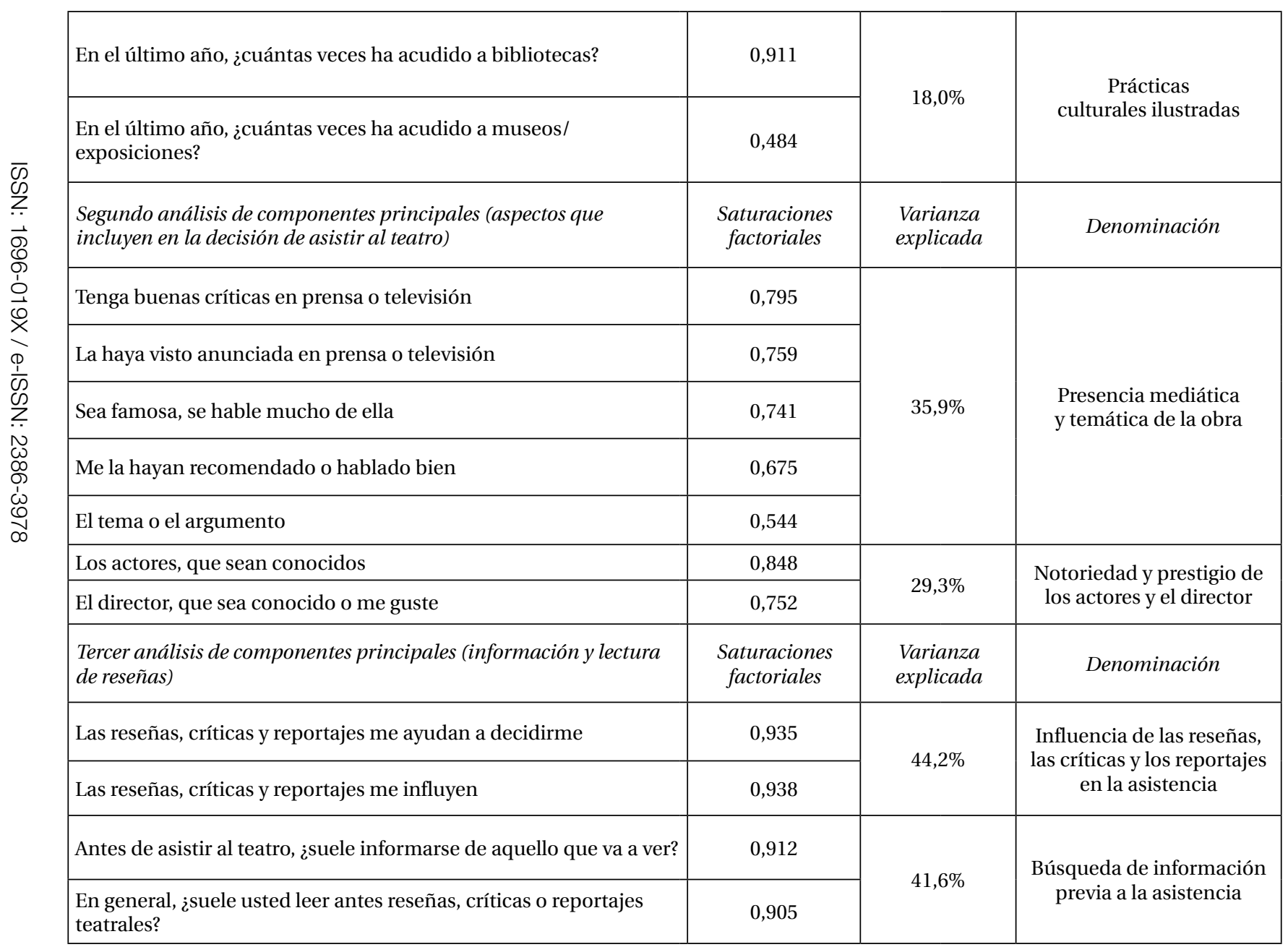

Unidad: saturaciones factoriales de la matriz de componentes rotados. Base: total muestra.

\section{Fuente: elaboración propia}


Una vez identificados los componentes que condensan los principales aspectos referidos a la asistencia al teatro, se procedió a la obtención de una tipología mediante la técnica del análisis de conglomerados (cluster analysis). Se han seguido las sugerencias de Hair, Anderson, Tatham y Black (1999) y Levy y Varela (2003), cuando señalan que éste debe constar de una primera fase de determinación del número de conglomerados y una segunda de optimización de los mismos. Así pues, en la primera, se aplicó un método jerárquico (método de Ward y distancia euclídea al cuadrado) para determinar el número adecuado de conglomerados y sus centros iniciales y, en la segunda, el método de optimización k-medias a partir de los centros iniciales obtenidos en la primera fase. La observación del dendograma y la pertinencia teórica de los conglomerados resultantes de la fase de optimización nos llevó a considerar como más apropiada la solución de cuatro grupos.

En segundo lugar, antes de proceder a examinar las características de cada uno de los conglomerados se realizó una triple comprobación de la validez de la clasificación obtenida a través del análisis de varianza unidireccional, el análisis discriminante y el análisis de la distancia entre los centroides (distancia euclídea). El análisis de varianza unidireccional (ANOVA) permite comprobar si las diferencias que cada una de las variables utilizadas producen en la formación de los agrupamientos son estadísticamente significativas. El ANOVA de la solución de cuatro conglomerados reveló que la variabilidad entre-grupos superaba la variabilidad intra-grupos $(p<0,001)$. También se recurrió al análisis discriminante, una técnica estadística que permite descubrir la proporción de personas que son correctamente clasificadas con la agrupación obtenida (Díaz de Rada, 2002: 310). En este caso, al llevar a cabo tal tipo de análisis utilizando como variable dependiente la pertenencia de cada persona a los cuatro conglomerados creados con el método $k$-medias, y como variables independientes las cinco variables derivadas de los análisis de componentes principales, el porcentaje de casos correctamente asignados alcanzó un 96\%. Por último, el examen de las diferencias de los conglomerados considerando la distancia entre los centroides (distancia euclídea), arrojó también resultados positivos. La tabla 2 muestra que los conglomerados más diferentes son el 1 y el 2, con una distancia de 4,922, mientras que los más parecidos son el 2 y el $4(2,299)$ y el 2 y el $3(1,729)$. En cualquier caso, todos los coeficientes son elevados, lo que indica que los conglomerados se diferencian claramente.

Tabla 2: Distancias entre los centros de los conglomerados finales

\begin{tabular}{|c|c|c|c|c|}
\hline Conglomerado & 1 & 2 & 3 & 4 \\
\hline 1 & -- & & & \\
\hline 2 & 4,922 & -- & & \\
\hline 3 & 4,074 & 1,729 & -- & \\
\hline 4 & 4,599 & 2,299 & 2,307 & -- \\
\hline
\end{tabular}

Fuente: elaboración propia

Una vez validada la clasificación en cuatro conglomerados, en la tabla 3 se presentan sus centros finales. El primer conglomerado incluye a un grupo de espectadores teatrales que supone un 5,1\% del total de la muestra y tiene una serie de características bien diferenciadas. Se trata, por un lado, del grupo de mayor asistencia e interés por el teatro, así también como el que mayor influencia reconoce a la notoriedad y prestigio de los actores y director de la obra en sus decisiones 
de asistir al teatro. Son también las personas que realizan una mayor búsqueda de información a través de la lectura de reseñas, críticas o reportajes antes de asistir a una representación teatral si bien son los que menos influencia sobre su decisión reconocen a esas búsquedas. También son los que menos influencia reconocen a la presencia de una obra en los medios de comunicación. Todo ello sugiere que se trata de consumidores teatrales celosos de su independencia de criterio, por lo que no resulta sorprendente que sean asistentes preferentes de representaciones de teatro alternativo, tal y como se muestra en la tabla 4. En la misma tabla 4 también se puede comprobar que contrariamente a lo que sucede en el total muestral, en este grupo hay más hombres que mujeres, predominan las personas de menos de 35 años que se encuentran en situación laboralmente activas y su estructura de estudios no difiere demasiado de la del conjunto de espectadores escénicos entrevistados. A tenor de las distintas características que se acaban de mencionar, este conglomerado bien podría recibir la denominación de informados-alternativos.

El segundo conglomerado obtiene puntuaciones relativamente positivas y cercanas a los promedios globales en cuatro de los cinco componentes, si bien destaca por ser el que mayor importancia otorga a la presencia mediática y a la temática de la obra de teatro; de hecho, es el único grupo en que este factor arroja un valor positivo. También adjudican una elevada importancia a la notoriedad del director y los actores. Por otro lado, se sitúan en un nivel intermedio en lo que se refiere a la búsqueda de información previa sobre la obra, lectura de reseñas y críticas sobre la obra y consumo e interés por el teatro. Agrupa a cerca de la mitad de los espectadores teatrales ( $45,5 \%$ de la muestra). Por lo que se refiere a sus características sociodemográficas, es el conglomerado con mayor presencia de mujeres y personas con estudios universitarios, así también como el más presente en representaciones de orientación comercial. Teniendo en cuenta que agrupan a la mitad de la muestra y que ninguno de los cinco componentes les diferencia de un modo especial podrían ser considerados como convencionales-comerciales.

El tercer conglomerado alberga a casi uno de cada tres consumidores escénicos $(30,8 \%)$ y presenta algunas similitudes con el conglomerado anterior aunque sus puntuaciones no tienden a ser tan extremas (tabla 3). En primer lugar, registra la segunda tasa de asistencia e interés por el teatro más elevada. En segundo lugar, es el grupo que menor influencia atribuye a la notoriedad del director de la obra y los actores en la decisión de asistir al teatro, al tiempo que reconoce una débil influencia a la presencia de la obra en los medios de comunicación, aunque no tanta como las personas integrantes del primer conglomerado. Por otro lado, es el grupo que realiza una mayor búsqueda de información previa sobre la obra, lectura de reseñas y críticas sobre la obra, si bien la influencia que reconoce a las reseñas, críticas y reportajes teatrales en su asistencia al teatro es media si se la compara con el resto de conglomerados. La estructura sociodemográfica de este conglomerado (tabla 4) no difiere demasiado de las características del conjunto de espectadores teatrales, si bien se caracterizan por ser el público que menos atraído se siente por el teatro clásico y contemporáneo. A tenor de todo ello, una denominación que podría hacer justicia a los rasgos diferenciales de este conglomerado es la de documentados-receptivos. El cuarto conglomerado presenta puntuaciones bajas en todos los componentes introducidos en el análisis. En primer lugar, es el grupo cuyo consumo e interés por el teatro se encuentra en el nivelo más bajo. Dan poca importancia a la presencia mediática y temática de la obra, así como a la notoriedad del director y los actores como aspectos que pueden tener importancia en su decisión de asistir a la representación de una obra teatral. Sin embargo, son el grupo que menos información, reseñas, críticas y reportajes sobre la obra consultan y, también, los que menos influidos se reconocen por 
estas reseñas y críticas. El conglomerado agrupa a un 18,7\% de los espectadores teatrales y está sobrerrepresentado por hombres y personas de 20 a 35 años. Este conglomerado tiene una menor presencia entre los consumidores de teatro alternativo y comercial y se encuentra sobrerrepresentado entre los habituales a representaciones clásicas y contemporáneas. El distanciamiento de las distintas influencias, así como el hecho de que sean los que menos información previa buscan y menos peso confieren a la lectura de críticas y reseñas sugiere que una denominación adecuada podría ser la de distantes-independientes.

Tabla 3: Análisis de conglomerados

\begin{tabular}{|l|c|c|c|c|}
\hline \multirow{2}{*}{ Componentes principales incluidos en el análisis } & \multicolumn{3}{|c|}{ Conglomerados } \\
\cline { 2 - 5 } & $\begin{array}{c}\text { Informados } \\
\text { alternativos }\end{array}$ & $\begin{array}{c}\text { Convencionales } \\
\text { comerciales }\end{array}$ & $\begin{array}{c}\text { Documentados } \\
\text { receptivos }\end{array}$ & $\begin{array}{c}\text { Distantes } \\
\text { independientes }\end{array}$ \\
\hline Consumo e interés por el teatro & 2,89024 & $-0,29032$ & 0,08372 & $-0,35105$ \\
\hline Presencia mediática y temática de la obra & $-2,45867$ & 0,64595 & $-0,35996$ & $-0,42333$ \\
\hline Notoriedad de los actores y el director de la obra & 0,94965 & 0,40244 & $-0,63009$ & $-0,25168$ \\
\hline $\begin{array}{l}\text { Influencia de las reseñas, las críticas y los } \\
\text { reportajes en la asistencia al teatro }\end{array}$ & $-1,46085$ & 0,52779 & $-0,11758$ & $-0,55663$ \\
\hline $\begin{array}{l}\text { Búsqueda de información previa a la asistencia } \\
\text { al teatro }\end{array}$ & 0,56157 & 0,09338 & 0,68995 & $-1,49899$ \\
\hline Presencia de cada conglomerado & $5,1 \%$ & $45,5 \%$ & $30,8 \%$ & $18,7 \%$ \\
\hline
\end{tabular}

Unidad: centros finales de los conglomerados. Base: total muestra. 
Una tipología de espectadores teatrales en función de la influencia de diversos prescriptores y el uso...

Tabla 4: Características sociodemográficas de los conglomerados

\begin{tabular}{|c|c|c|c|c|c|c|c|c|}
\hline & & \multicolumn{4}{|c|}{ Conglomerados } & \multirow[t]{2}{*}{ Total } & \multicolumn{2}{|c|}{ Chi-Square Test } \\
\hline & & $\begin{array}{l}\text { Informados } \\
\text { alternativos }\end{array}$ & $\begin{array}{c}\text { Convencionales } \\
\text { comerciales }\end{array}$ & $\begin{array}{l}\text { Documentados } \\
\text { receptivos }\end{array}$ & $\begin{array}{c}\text { Distantes } \\
\text { independientes }\end{array}$ & & Valor & $p$ \\
\hline \multirow{2}{*}{ Sexo } & Varón & 60,0 & 27,8 & 44,3 & 54,1 & 39,4 & \multirow{2}{*}{10,821} & \multirow{2}{*}{$<0,05$} \\
\hline & Mujer & 40,0 & 72,2 & 55,7 & 45,9 & 60,6 & & \\
\hline \multirow{4}{*}{ Edad } & 20-35 años & 50,0 & 40,0 & 37,7 & 51,4 & 41,9 & \multirow{4}{*}{12,313} & \multirow{4}{*}{ ns } \\
\hline & 36-49 años & 20,0 & 28,9 & 24,6 & 32,4 & 27,8 & & \\
\hline & 50-65 años & 10,0 & 23,3 & 34,4 & 13,5 & 24,2 & & \\
\hline & $\begin{array}{l}\text { Más de } 65 \\
\text { años }\end{array}$ & 20,0 & 7,8 & 3,3 & 2,7 & 6,1 & & \\
\hline \multirow[t]{2}{*}{ Estudios } & $\begin{array}{l}\text { No } \\
\text { universitarios }\end{array}$ & 30,0 & 19,1 & 21,3 & 29,7 & 22,3 & \multirow{2}{*}{2,078} & \multirow{2}{*}{ ns } \\
\hline & Universitarios & 70,0 & 80,9 & 78,7 & 70,3 & 77,7 & & \\
\hline \multirow{5}{*}{$\begin{array}{l}\text { Situación } \\
\text { laboral }\end{array}$} & Trabaja & 80,0 & 58,9 & 70,5 & 64,9 & 64,6 & \multirow{5}{*}{15,103} & \multirow{5}{*}{ ns } \\
\hline & Jubilado & 20,0 & 14,4 & 6,6 & 2,7 & 10,1 & & \\
\hline & Parado & -- & 15,6 & 21,3 & 21,6 & 17,7 & & \\
\hline & Estudiante & -- & 7,8 & 1,3 & 8,1 & 5,6 & & \\
\hline & Ama de casa & -- & 3,3 & -- & 2,7 & 2,0 & & \\
\hline \multirow{3}{*}{$\begin{array}{l}\text { Sala } \\
\text { teatral }\end{array}$} & $\begin{array}{l}\text { Teatro } \\
\text { alternativo }\end{array}$ & 90,0 & 25,6 & 49,2 & 21,6 & 35,4 & \multirow{3}{*}{30,764} & \multirow{3}{*}{$<0,01$} \\
\hline & $\begin{array}{l}\text { Teatro clásico/ } \\
\text { actual }\end{array}$ & -- & 31,1 & 23,0 & 51,4 & 30,8 & & \\
\hline & $\begin{array}{l}\text { Teatro } \\
\text { comercial }\end{array}$ & 10,0 & 3,3 & 27,9 & 27,0 & 33,8 & & \\
\hline
\end{tabular}

Unidad: porcentajes verticales. Base: total muestra.

Fuente: elaboración propia

\section{Conclusiones}

Este estudio ha partido de la conveniencia de elaborar una tipología de espectadores teatrales que tenga en cuenta la influencia de los medios de comunicación, así como de otras instancias de prescripción en sus decisiones de asistir a representaciones teatrales, aspecto este que, como se ha visto en la amplia revisión bibliográfica de la primera parte del trabajo, no ha sido abordado por ninguna investigación previa. Con ese propósito se diseñó un cuestionario ad hoc y 
se realizó una encuesta a 210 asistentes a representaciones teatrales de tres salas de la ciudad de Valencia de perfil bien diferenciado (alternativo, comercial y clásico-actual). A partir de 18 variables que contenían información relativa a la asistencia e interés por el teatro, búsqueda de información teatral, consulta de críticas y reseñas teatrales se han efectuado diversos análisis estadísticos multivariables que han permitido identificar una tipología de cuatro tipos de consumidores escénicos. Esta tipología pone de manifiesto que los consumidores escénicos de la ciudad de Valencia difieren en la influencia que asignan a la presión mediática, el contenido temático de la representación o el prestigio y la notoriedad de la dirección y el reparto de la obra, así como en la intensidad con la que se busca información y se consultan noticias, reseñas y reportajes teatrales en los medios de comunicación.

Más concretamente, frente al conglomerado de convencionales-comerciales que agrupa a un tipo de espectador poco diferenciado del promedio global -por tanto, amorfo, en el sentido de sin forma diferenciada-, que supone cerca de la mitad de la muestra y hace gala de una mayor orientación hacia las representaciones teatrales de carácter comercial y masivo, han sido identificados otros tres conglomerados cuyos perfiles muestran unas aristas bien definidas. Así, por un lado estarían los informados-alternativos, con un elevado consumo teatral y una clara propensión a la búsqueda de información sobre la obra antes de acudir a la representación. Se trata de un grupo minoritario que se nutre muy especialmente de teatro alternativo. Asisten muy frecuentemente al teatro y se informan de manera abundante, mientras admiten poca influencia de la lectura de reseñas y reportajes o de la presión mediática hacia una obra. Mayor presencia cuantitativa tiene, por otro lado, el conglomerado de los distantes-independientes, un grupo de consumidores escénicos que se muestra distante de todas las instancias de prescripción consideradas en el análisis, aunque especialmente de aquellas que proceden de los críticos teatrales y los medios de información. Este grupo se compone de consumidores escénicos que suelen frecuentar los tres tipos de salas considerados en el análisis si bien parecen destacar por su mayor presencia en las representaciones que genéricamente se han definido como clásicas y actuales. Por último, el grupo de los documentados-receptivos integra a uno de cada tres consumidores escénicos cuya principal característica es la atención que prestan a las críticas, reseñas y reportajes sobre las obras teatrales así como la credibilidad que estas les merecen y la influencia que les confieren en sus decisiones de asistir al teatro.

Esta clasificación de los espectadores teatrales de la ciudad de Valencia plantea la existencia de una audiencia plural que corrobora el trabajo de otros investigadores que han sugerido la existencia de diferentes tipos de espectadores frente a la creencia de que exista un único tipo de consumidor. Su identificación permite diseñar estrategias y actuaciones dirigidas a cada uno de los grupos, por lo que pueden tomarse como base para la toma de decisiones en un proceso de marketing mix (Colomer, 2011): la elección de contenidos de la programación, el sistema de precios, el sistema de venta y el plan de comunicación.

\section{Referencias bibliográficas}

Ariño, A. (2010). Prácticas culturales en España: desde los años sesenta hasta la actualidad. Barcelona: Ariel.

Ateca-Amestoy, V. (2008). Determining heterogeneous behavior for theater attendance. Journal of Cultural Economics, 32 (2), pp. 127-151. http://dx.doi.org/10.1007/s10824-008-9065-Z 
Azpillaga, P. (2010). Conocimiento de los públicos. Escenium, Foro internacional de las artes escénicas [Bilbao, 10-12 de febrero de 2010].

Berenguer Contrí, G. y Cuadrado García, M. (2003). El comportamiento del consumidor de actividades en vivo. Experiencias y técnicas en la gestión del ocio, pp. 161-168. Universidad de Deusto.

Bergadaà, M. y Nyeck, S. (1995). Quel marketing pour les activités artistiques: Une analyse qualitative comparée des motivations des consommateurs et producteurs de théâtre. Recherche et Applications en Marketing, 10 (4), pp. 27-45. http:// dx.doi.org/10.1177/076737019501000402

Bourdieu, P. (2010). El sentido social del gusto: elementos para una sociología de la cultura. Buenos Aires: Siglo XXI.

Cantón García, J. A. (2004). Prensa y música: Divulgación y crítica. Comunicar: Revista científica iberoamericana de comunicación y educación, (23), pp. 43-47.

Colbert, F. y d'Astous, A. (2003). La consultation de critiques de films et son impact sur la consommation. Gestion, 28 (1), pp. 12-17. http://dx.doi.org/10.3917/riges.281.0012

Colbert, F. (2007). Le marketing des arts et de la culture. Montréal: Gaëtan Morin.

Colbert, F. y Cuadrado García, M. (2003). Marketing de las artes y la cultura. Barcelona: Ariel.

Colombo, A. (2010). Desarrollo de los públicos actuales. Escenium, Foro internacional de Artes Escénicas [Bilbao, 10-12 de febrero de 2010].

Colomer, J. (2013). La formación y gestión de públicos escénicos en una sociedad tecnológica. Madrid: Fundación Autor.

Colomer, J. (2011). Cómo gestionar la diversidad de públicos teatrales. Las puertas del drama: revista de la Asociación de Autores de Teatro, 39, pp. 18-21.

Cuadrado García, M. (1998). Los beneficios buscados como criterio de segmentación en el sector de las artes escénicas. Investigaciones Europeas de Dirección y Economía de la Empresa, 4 (2), pp. 31-44.

Cuadrado García, M. (2000). Consumo de actividades teatrales y musicales: Hacia una tipología de los espectadores escénicos. Distribución y Consumo, 10 (51), pp. 118-136.

Cuadrado García, M. y Berenguer Contrí, G. (2002). El consumo de servicios culturales. Madrid: ESIC.

Diggle, K. (1994). Arts marketing. London: Rhinegold.

Fernández Torres, A. (1996). Público y repertorio en el teatro español actual. ADE teatro: Revista de la Asociación de Directores de Escena de España, 50, pp. 32-42.

Fernández Torres, A. (2011). Reflexiones sobre el público teatral: La variable dependiente. Las puertas del drama: revista de la Asociación de Autores de Teatro, 39, pp. 8-17.

Fernández Torres, A. (2012). El público de teatro en la españa del siglo XXI. Madrid: Instituto Nacional de las Artes Escénicas y de la Música: Centro de Documentación Teatral.

Hair, J. F; Anderson, R. E.; Tatham, R. L. y Black, W. (1999). Análisis Multivariante. Madrid: Prentice Hall. 
Haley, R. I. (1968). Benefit segmentation: A decision-oriented research tool. Journal of Marketing (pre-1986), 32, pp. 30. Jiménez López, L. (2000). Teatro \& públicos: el lado oscuro de la sala. México, D.F.: Escenología.

Jiménez López, L. (2010). Artes escénicas, públicos y sustentabilidad en el siglo XXI. Escenium, Foro internacional de las artes escénicas [Bilbao, 10-12 de febrero de 2010].

Kelly, R. F. (1987). Culture as commodity: The marketing of cultural objects and cultural experiences. Advances in Consumer Research , 14, pp. 347-351.

Kotler, P. y Scheff, J. (1997). Marketing de las artes escénicas. Madrid: Fundación Autor.

Lévy, J.P. y Varela, J. (2003). Análisis multivariable para las ciencias sociales. Madrid: Pearson Educación.

Logroño, M.T. (2016). Influencias y prescriptores del consumo teatral. Un estudio sobre el efecto de las críticas teatrales y otras instancias de prescripción en los hábitos de asistencia al teatro. Estudios sobre el Mensaje Periodístico, 22, pp. 391-410.

Logroño, M.T. y Llopis, R. (2017). La comunicación cultural y los públicos del teatro ISSN: 1575-2100. Ambitos. Revista de Estudios de Ciencias Sociales y Humanidades, 37, pp. 83-93.

Logroño, M.T. (2018). La contribució de les tecnologies digitals al desenvolupament del sector de les arts escèniques. Implicacions en els processos de creació, difusió i consum i la seua influència en els públics de la ciutat de València. València: Universitat de València.

López Sintas, J. y García Alvarez, E. (2002). El consumo de las artes escénicas y musicales en España: comportamiento, valores y estilos de vida de los consumidores. Madrid: Fundación Autor.

Mayaux, F. (1987). Le marketing au service de la culture. Revue française du marketing, 113, pp. 37-48.

Nantel, J. (2007). La segmentation et le positionnement. En F. Colbert (Ed.). Le marketing des arts et de la culture, pp. 121149. Québec: Gaëtan Morin Éditeur.

Ramon, G. y Basso, A. L. (2010). Hacia un mapa de públicos de las artes escénicas a partir de principales estudios sobre públicos culturales a nivel internacional. Escenium, Foro internacional de las artes escénicas [Bilbao, 10-12 de febrero de 2010].

Sánchez de Horcajo, J. J. (1999). Los teatros madrileños: un estudio sociológico. Madrid: Ediciones Libertarias.

Sellas, J. y Colomer, J. (2009). Marketing de las artes escénicas: creación y desarrollo de públicos. Barcelona: Bissap Consulting.

Urrutia, J. (1991). El espectador implícito como condicionador de la recepción teatral. ADE teatro: Revista de la Asociación de Directores de Escena de España,22, pp. 53-57.

Watson, B. (1971). Los públicos de arte. En A. Silberman, P. Bourdieu, R. L. Brown, R. Clausse, V. Karbusicky, H. O. Luthe y B. Watson (eds.). Sociología del arte, pp. 177-199. Buenos Aires: Ediciones Nueva Visión.

Wright, E. A. y Glanz, M. (1962). Para comprender el teatro actual: cine, teatro y televisión. México: Fondo de Cultura Económica. 